[Agr. Biol. Chem., Vol. 27, No. 7, p. 484 490, 1963]

\title{
Biochemical Studies on Fatty Liver
}

\author{
Part II. Effects of Amino Acid Supplements on Fatty Liver \\ By Masaji Ogura and Nobuzo Nakamura \\ Department of Agricultural Chemistry, Faculty of Agriculture, \\ University of Utsunomiya, Utsunomiya \\ Received January 28, 1963
}

\begin{abstract}
The effects on the fat content in livers of amino acid supplements to various cereal diets at $1.12 \%$ dietary nitrogen level, which causes fatty livers in young rats, have been investigated. When rats are fed on diets supplemented with amino acid to retain the requirement pattern of essential amino acids, they grow very well, but the accumulation of liver fat fails to decrease. However, when a part of the requirement pattern diets is replaced with $0.30 \%$ of L-threonine, the deposition of liver fat shows a clear decrease. The results obtained suggest that this excess part of threonine has a specific action for the prevention of fat deposition in livers regardless of protein utilization, together with the so-called "supplementary effects" of amino acids.
\end{abstract}

\section{INTRODUCTION}

In the previous report ${ }^{1)}$, the authors reported that the rats fed on the diets of polished rice, wheat flour or corn as protein sources, at $1.12 \%$ dietary nitrogen level, developed fatty livers, but that, if the diets were at $1.60 \%$ nitrogen level, the accumulation of liver fat was reduced to the normal level. Then it was assumed that, even at $1.12 \%$ nitrogen level, if other proteins of higher nutritive value were used, or if these diets were supplemented with some amino acids, liver fat would probably decreased.

The present study is therefore designed to confirm the effects of amino acid supplements on the fat content in livers. The authors have obtained the results from experiments that the previous assumption must be partly amended in the following point; that is, the liver fat deposition does not decrease only by the so-called "supplementary effects" of amino acids, which lead to the increase of protein

1) M. Ogura, H. Ohba, I. Kinoshita and N. Nakamura, J. Agr. Chem. Soc. Japan, 36, 842 (1962). utilization, but it is also reduced to the normal level when the requirement pattern diets are partly replaced with a small quantity of threonine. This suggests that threonine has a specific action for the prevention of the fat deposition in the liver. The relations between the fat content in the liver and the value of caloric intake per retained nitrogen, and the iodine value of the liver fat are also discussed in this paper.

\section{EXPERIMENTAL}

Male weanling rats of the Wistar strain weighing from 50 to $60 \mathrm{~g}$ were divided into similar groups of 5 animals each and maintained in individual cages. The animals were fed on experimental diets and water ad libitum, and were weighed on alternate days during the experimental period of 20 days. The same season as in the previous study was chosen for the feeding of the animals.

Experiment I. The composition of experimental diets for 5 groups is summarized in Table $I$. The control group corresponds to the rice group in the previous study. The line of amino acids in Table I shows the total supplemental amount of essential amino acids. Table II shows the supplemental 
TABLE I. COMPOSITION OF EXPERIMENTAL DIETS*1)

Group
$\begin{aligned} & \text { Polished rice } \\ & \text { Wheat flour }\end{aligned}$
Corn

TABle II. SupPlemental Amount of INDIVIDUAL AMINO ACID*1)

(Experiment I)

Control $\overbrace{\text { I }}^{\text {Requirement pattern groups }}$

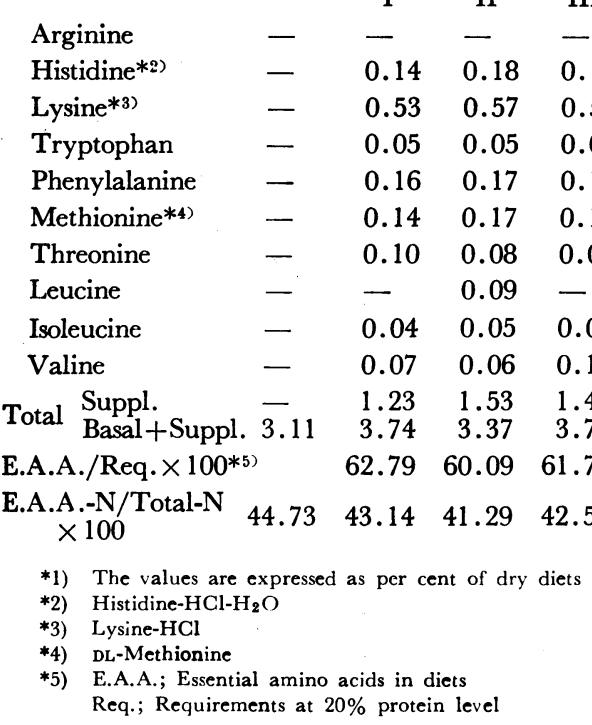

TABLE III. AMINO ACID COMPOSITION OF VARIOUS Gereal DIETS*1) AND AMINO ACID REQUIREMENTS OF YOUNG RATS*2)

\begin{tabular}{|c|c|c|c|c|}
\hline & Rice & $\begin{array}{l}\text { Wheat } \\
\text { flour }\end{array}$ & Corn & $\begin{array}{c}\text { Require } \\
\text { ments }\end{array}$ \\
\hline Arginine & 0.55 & 0.30 & 0.31 & 0.2 \\
\hline Histidine & 0.17 & 0.13 & 0.17 & 0.4 \\
\hline Lysine & 0.24 & 0.17 & 0.19 & 1.0 \\
\hline Tryptophan & 0.08 & 0.08 & 0.05 & 0.2 \\
\hline Phenylalanine & 0.33 & 0.31 & 0.31 & 0.7 \\
\hline Methionine & 0.13 & 0.08 & 0.13 & 0.4 \\
\hline Threonine & 0.25 & 0.27 & 0.29 & 0.5 \\
\hline Leucine & 0.59 & 0.48 & 0.89 & 0.8 \\
\hline Isoleucine & 0.33 & 0.31 & 0.28 & 0.5 \\
\hline Valine & 0.44 & 0.31 & 0.37 & 0.7 \\
\hline
\end{tabular}

*1) The values are expressed as per cent of the diets at $1.12 \%$ nitrogen level

*2) The values are expressed as per cent of the diets at $20 \%$ protein level

amount of individual amino acid. Table III includes the composition of amino acids of each diet at $1.12 \%$ nitrogen level (the value of which has been calculated based upon the literature of Block $^{2)}$ ), in comparison with the amino acid requirements of young rats at

2) R.J. Block, "Amino Acid Handbook" Charles C. Thomas Publisher, 1956, p. 346 . 
$20 \%$ protein level $^{3)}$. In experiment $I$ this requirement pattern has been adopted as the standard of amino acid supplements.

As shown in Table III, the content of arginine in each diet and the content of leucine in corn are relatively high. In the prepared diets, accordingly, the excess amounts of arginine in group I and II and of arginine and leucine in group III are unavoidable. The diets for group IV consist of polished rice with $0.40 \%$ of lysine, $0.30 \%$ of threonine and $0.10 \%$ of tryptophan, in which the amount of rice corresponding to the quantity of nitrogen contained in these amino acids is deducted from that of the control group, and instead starch is added to them to make up $100 \%$.

Experiment 2. The composition of the experimental diets for 3 groups is shown in Table $I$. These diets contain $0.30 \%$ of threonine in addition to the diets

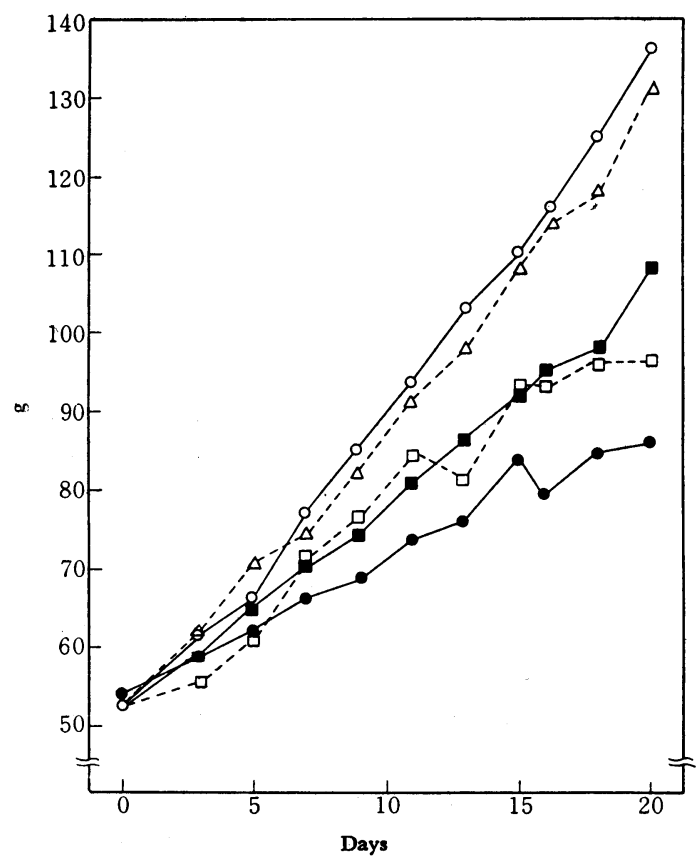

FIG. 1. Growth Curves of Rats in Each Group (Experiment 1).

Each curve is plotted with the mean for a group of 5 rats.

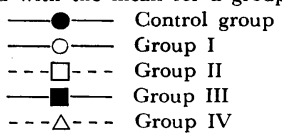

3) R.J. Block, “Amino Acid Handbook" Charles C. Thomas Publisher, 1956, p. 165. in experiment $I$, and the part of the requirement pattern diets equivalent to the quantity of nitrogen contained in $0.30 \%$ threonine is deducted and instead starch is added to make up $100 \%$. The supplemental amount of individual amino acid is saved to describe.

Estimation. The estimation and the expression of the results for growth curve, rate of gain, nitrogen efficiency ratio, fat content in liver, iodine value of liver fat etc. were carried out in the same method as in the previous study. Nitrogen efficiency ratio and value of caloric intake per retained nitrogen were estimated for 3 days of the $17 \mathrm{th} \sim 19$ th day of the experimental period.

\section{RESULTS AND DISCUSSION}

Experiment 1. Growth curves of each group are illustrated in Fig. 1. The rate of gain and nitrogen efficiency ratio are recorded in Table IV. Amino acid supplements cause the remarkable growth of animals in each group. Especially the growth of group I and IV in

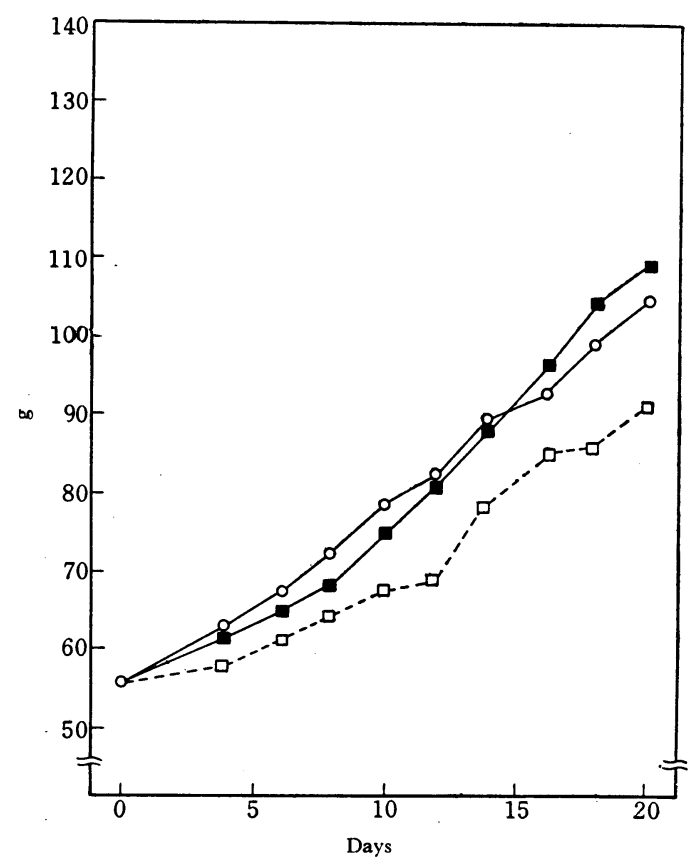

FIG. 2. Growth Curves of Rats in Each Group (Experiment 2).

Each curve is plotted with the mean for a group of 5 rats. - - - G - Group I - Group II 
TABle IV. EFFECT OF AMINO ACID SUPPlementS ON RATE OF GAIN AND NITROGEN EFFICIENCY RATIO OF RATS FED ON VARIOUS Gereal Diets

$\begin{array}{ccc}\text { Experiment } 1 & \begin{array}{c}\text { Rate of Gain } \\ \text { (g/week) }\end{array} & \begin{array}{c}\text { Nitrogen Efficiency } \\ \text { Ratio }\end{array} \\ \text { Control } & 11.7 \pm 0.6^{*} & 14.43 \pm 2.0^{*} \\ \text { I } & 29.6 \pm 0.7 & 28.08 \pm 0.9 \\ \text { II } & 15.8 \pm 0.8 & 18.13 \pm 2.4 \\ \text { III } & 19.1 \pm 1.3 & 20.05 \pm 2.0 \\ \text { IV } & 27.4 \pm 1.2 & 21.25 \pm 2.6 \\ \text { Experiment } 2 & & \\ \text { I } & 17.8 \pm 1.6 & 31.83 \pm 1.3 \\ \text { II } & 13.2 \pm 0.8 & 22.46 \pm 3.5 \\ \text { III } & 18.5 \pm 1.8 & 22.82 \pm 2.0 \\ \text { * The values represent m.ean } \pm \text { standard error of the mean for } \\ \text { a group of 5 rats }\end{array}$

experiment $I$ is equal to that of the group with rice diets at $1.60 \%$ nitrogen level in the previous study. There is a significant difference between the final body weight of group I, IV and that of group II, III $(\mathrm{p}<$ $0.01)$. It is interesting to assume that the difference caused in the growth in spite of the equalization of the pattern of essential amino acids and the dietary nitrogen level may be due to the following factors; first, the difference of the composition of non-essential amino acids in protein source, second, the little unavoidable differences of the actual amounts of essential amino acids after preparation. The fact that the growth of group IV is equal to that of group I is also interesting. Table IV indicates that, as the effect of amino acid supplements, not only food intake but also nitrogen efficiency ratio increases remarkably.

Fat content in livers is recorded in Table V. The liver fat of group I does not show a significant difference from that of the control group, and those of group II and III show a significant increase $(\mathrm{p}<0.05)$. These results are contrary to the expectation of the authors. On the other hand, it should be noted that the liver fat of group IV shows a decrease to
TABle V. EFFEct of Amino Acid Supplements ON LIVER FAT AND ITS IODINE VALUE OF RATS FED ON VARIOUS GEREAL DIETS

$$
\begin{gathered}
\text { Liver fat } \\
\text { (dry weight) } \% \quad \text { Iodine value }
\end{gathered}
$$

Experiment I

$\begin{array}{llr}\text { Control } & 18.00 \pm 1.35^{*} & 90.35 \pm 3.79 * \\ \text { I } & 21.20 \pm 0.85 & 79.93 \pm 2.03 \\ \text { II } & 24.47 \pm 1.85 & 83.30 \pm 1.20 \\ \text { III } & 24.59 \pm 2.36 & 85.76 \pm 2.43 \\ \text { IV } & 12.24 \pm 0.14 & 100.83 \pm 1.33\end{array}$

Experiment 2

$\begin{array}{lcr}\text { I } & 13.97 \pm 1.51 & 93.72 \pm 1.31 \\ \text { II } & 13.29 \pm 1.07 & 84.57 \pm 4.45 \\ \text { III } & 14.23 \pm 0.94 & 93.31 \pm 2.41 \\ \text { represent } & \text { mean } \pm \text { standard error of the mean for }\end{array}$

* The values represen
a group of 5 rats

the normal level. The difference between group IV and the control group is significant at $1 \%$ level. This difference was also determined by the histochemical technique with Hematoxylin-Eosine or Osmic acid stain.

These results indicate that the amino acid supplements for the requirement pattern bring no effect on the decrease of liver fat though they have a remarkable effect on the growth, but that the diets containing a particular composition of amino acid differing from the requirement pattern diets, for example, those for group IV, are able to prevent the fatty liver.

Many studies on the effect of amino acid on the fatty liver have already been carried out. Harper et al.4) have reported that (I) the inclusion of $0.2 \%$ of $\mathrm{L}$-lysine $\cdot \mathrm{HCl}$ and $0.24 \%$ of DL-threonine in the rice diet did not prevent the accumulation of liver fat, however, (2) the fat content of the liver was normal when $0.4 \%$ of L-lysine $\cdot \mathrm{HCl}$ was included with either $0.24 \%$ or $0.5 \%$ of DLthreonine. Supplements of other amino acids were without effect on the deposition of liver fat.

4) A.E. Harper, M.E. Winje, D.A. Benton and C.A. Elvehjem, $J$. Nutrition, 56, 187 (1955). 
Singal et al.5) have suggested that, although no fatty liver was caused when rats were fed on amino acid mixture simulating 9\%-casein which was lacking in threonine or lysine, (I) the liver fat increased with increase of the amount of lysine or threonine, and (2) when lysine or threonine was included over a definite amount, a decrease of the liver fat was found.

And the facts that, in $9 \%$-egg albumin diets, $1.8 \%$ of threonine brought no effect on the reduction of the liver fat, but $1.5 \%$ of glycine was able to reduce the liver fat, and when threonine was supplemented together with lysine and histidine the fatty liver was prevented, have been presented by Winje et al. ${ }^{6}$

Harper et al. ${ }^{7}$ and Benton et al.8) have suggested also the reducing effect of nonessential amino acids on the fatty liver.

As described above, the certain amino acid shows the reducing effect on the liver fat under the certain condition, therefore, although this effect seems to be changeable according to the quantitative or qualitative variation of protein source or other factor, the result of group IV seems to be a similar phenomenon as (2) of the results by Harper et al.4) and Singal et al.5) which are described above, and the results of group I, II and III seems to be similar as (I) of their results. From these results, since the diets for group IV are relatively rich in the content of threonine as compared with those for group I, II and III, it is assumed that, if the diets of group I, II and III are further supplemented with threonine, the liver fat will probably decrease.

Then, according to the views of A. Yoshida and $\mathrm{K}$. Ashida ${ }^{9}$, who have recently reported their study on amino acid imbalance that the fatty liver is caused by the disproportionately high intake of calories against the intake of balanced protein, the relation between caloric intake and retained nitrogen was examined. As shown in Table VI, the value of caloric intake per retained nitrogen in the amino

TABle VI. EFFect of Amino Acid Supplements on Value of Galoric Intake PER RETAINED NITROGEN OF RATS FED ON VARIOUS GEREAL DIETS

\begin{tabular}{|c|c|c|c|c|c|c|}
\hline & $\begin{array}{l}\text { Cal. of diets } \\
100 \mathrm{gm}\end{array}$ & $\begin{array}{l}\text { Cal. intake } \\
/ 3 \text { days }\end{array}$ & $\begin{array}{l}\mathrm{N} \text { intake } \\
\mathrm{mg} / 3 \text { days }\end{array}$ & $\begin{array}{l}\text { Retained } N \\
\mathrm{mg} / 3 \text { days }\end{array}$ & $\begin{array}{c}\mathrm{N} \text { retention } \\
\%\end{array}$ & $\begin{array}{l}\text { Cal. intake per } \\
\mathrm{g} \text { retained } \mathrm{N}\end{array}$ \\
\hline \multicolumn{7}{|c|}{ Experiment I } \\
\hline Control & $421.6^{* 1)}$ & $110.0 \pm 10.5^{* 2)}$ & $292.3 \pm 28.0^{* 2)}$ & $149.2 \pm 25.9^{* 2}$ & $50.8 \pm 7.2^{* 2)}$ & $785.7 \pm 17.9^{* 2)}$ \\
\hline I & 422.0 & $188.5 \pm 2.8$ & $500.1 \pm 7.5$ & $360.1 \pm 5.2$ & $72.0 \pm 0.7$ & $523.4 \pm 4.9$ \\
\hline II & 417.1 & $123.4 \pm 17.4$ & $331.3 \pm 46.7$ & $180.1 \pm 28.7$ & $54.2 \pm 3.8$ & $697.4 \pm 49.5$ \\
\hline III & 417.4 & $155.4 \pm 8.3$ & $417.0 \pm 22.4$ & $288.4 \pm 19.9$ & $65.7 \pm 2.7$ & $568.7 \pm 24.0$ \\
\hline IV & 421.8 & $179.1 \pm 9.1$ & $475.4 \pm 24.1$ & $335.8 \pm 20.6$ & $70.8 \pm 3.7$ & $536.3 \pm 28.9$ \\
\hline \multicolumn{7}{|c|}{ Experiment 2} \\
\hline I & 422.0 & $138.5 \pm 5.3$ & $367.7 \pm 14.1$ & $266.2 \pm 16.3$ & $74.2 \pm 2.6$ & $509.9 \pm 18.1$ \\
\hline II & 417.7 & $121.9 \pm 8.7$ & $327.0 \pm 23.2$ & $250.4 \pm 21.4$ & $76.3 \pm 1.6$ & $489.8 \pm 10.9$ \\
\hline III & 418.2 & $152.4 \pm 7.0$ & $408.0 \pm 20.2$ & $259.9 \pm 22.3$ & $63.2 \pm 2.5$ & $593.5 \pm 23.2$ \\
\hline & Calculated value & & & & & \\
\hline
\end{tabular}

5) S.A. Singal, S.J. Hazan, V.P. Sydenstricker and J.M. Ljttlejohn J. Biol. Chem., 200, 867 (1953).

6) M.E. Winje, A.E. Harper and C.A. Elvehjem, J. Nutrition, 54, 155 (1954).

7) A.E. Harper, W.J. Monson, D.A. Benton, M.E. Winje and C.A. Elvehjem, J. Biol. Chem., 206, 151 (1954).

8) D.A. Benton, A.E. Harper, M.E. Winje and C.A. Elvehjem, ibid., 214, 677 (1955). acid supplemented groups shows a considerable decrease, compared with that in the control group. However, even though the value of caloric intake per retained nitrogen

9) A. Yoshida and K. Ashida, This Journal, 26, 56 (1962). 
decreases, if the value remains in the range of the disproportionately high intake of calories, it seems natural that no decrease is observed in the liver fat. In fact, this value at $1.60 \%$ dietary nitrogen level in the previous report, or this value in the data by A. Yoshida and K. Ashida ${ }^{9)}$ when the liver fat is in the normal level, is lower than the value obtained in Table VI. The cause of no decrease of the liver fat, consequently, may be explained by the relation of caloric intake and retained nitrogen, and the assumption in previous report must partly be amended. In addition to these facts, the authors take notice the following points; 1) it is likely that there is a certain condition which causes the decrease of the deposit fat in the liver, even in the range of the disproportionately high intake of calories against retained nitrogen. 2) and a significant difference may occur in the fat content of the liver though no difference in the value of caloric intake per retained nitrogen is observed.

This suggests that the fat content in the liver cannot be explained only by the relation of caloric intake and retained nitrogen, considering the result that the value of group I, II and III shows decrease, whereas the liver fat of these group shows tendency of increase.

Experiment 2. As described already, since the diets for group IV in experiment $I$ are relatively rich in the content of threonine as compared with those for requirement pattern groups, there is a possibility that this excess part of threonine may have a specific action for the restriction of the accumulation of the liver fat, together with the so-called "supplementary effects" of amino acids. In order to confirm this, in experiment 2 a part of requirement pattern diets was replaced by $0.30 \%$ of threonine, in which the feeding of animals was carried out at the same nitrogen level as in experiment $\mathbf{I}$.

The results obtained are shown in the Tables, each together with the results of experiment I.

Growth curves are illustrated in Fig. 2. The authors are impressed by the fact that the growth of group $I$ in experiment 2 is inferior to that of group $\mathrm{I}$ in experiment $\mathrm{I}$, which is considered to be caused by the decrease of food intake (EXP. I, 44.7 \pm 0.7 , EXP. 2, 32.8 $\pm 1.3, \mathrm{~g} / 3$ days) .

The liver fat in each group of experiment 2 , decreases to the normal level. The difference between these groups and the control group is significant at $5 \%$ level, and the difference between these groups and the corresponding groups in experiment $I$ is significant at $1 \%$ level. These results are considered to support the assumption on threonine supplements which is described in the discussion of experiment I. However, in views of the result by Elvehjem ${ }^{10}$ ) that, in comparing rice and wheat diets, the change of the liver fat cannot be explained only by the content of threonine in diets, and of the results by Harper et al.4) and Singal et al.5) which are described before, it must be emphasized also in this case that this specific action of threonine is found under the coexistence with other amino acids, above all lysine.

The value of caloric intake per retained nitrogen in group I and III shows no difference between experiment 1 and 2 . Therefore, it is suggested that the excess part of threonine has no effect on the value of caloric intake per retained nitrogen. In the same comparison, group II shows no change in food intake but the value of caloric intake per retained nitrogen shows a considerable decrease because of the significant increase of nitrogen retention in experiment 2. This seems to show the excess threonine heightens

10) C.A. Elvehjem, Fed. Proc., 15, 965 (1956). 
protein utilization as far as this result is concerned. But the body gain of group II during the period of the estimation of this value in experiment 1 is remarkably less than the average body gain throughout all the experimental period. So the authors find the contradictory result that the supplementary effect of amino acids failed to appear at all during this period. It may be because the animals met with some hindrance during this period. Here the authors may suppose that the average value of retained nitrogen in experiment 1 is higher than the value obtained. As it seems more reasonable to assume that the retained nitrogen unusually decreased during this period in experiment 1 than to assume that it increased in experiment 2, the authors should avoid the discussion about the change of the value of caloric intake per retained nitrogen in group II between experiment 1 and 2.

The iodine value of liver fat is given in Table V. In experiment 1 there is not considerable difference among the control group, group I, II and III, but the value of group IV is higher than those of the others. The difference is significant at $1 \%$ level. In experiment 2, the iodine value of liver fat of group I, II and III is higher than those in experiment 1 and a significant difference is not observed between these groups and group IV in experiment 1 . The difference of the iodine value of liver fat caused by the kind of protein sources, which was observed between rice and wheat flour diets in the previous study, completely disappeared. This result suggests that the difference on the iodine value of liver fat caused by the variation of protein sources has disappeared through the amino acid supplements, and that as the result, the iodine value is mainly conditioned by that of the deposit fat in livers derived from dietary fat, which has the lower iodine value than normal liver fat. This suggestion can explain the fact that the iodine values of the control group, group I, II and III in experiment 1, which develop fatty liver, are lower than those of group IV, and that those of group I, II and III in experiment 2 rise with the decrease of liver fat.

Acknowledgements. The authors are grateful to Mr. Seiji Yokoyama and Mr. Yukio Yajima in this Laboratory for their generous assistance in the course of these experiments. 